\title{
Article
}

\section{Accelerating directional charge separation via built-in interfacial electric fields originating from work-function differences}

\author{
Chao Xue a, Hua An b, Guosheng Shao a, Guidong Yang b,* \\ a State Centre for International Cooperation on Designer Low-carbon and Environmental Materials (CDLCEM), School of Materials Science and Engineer- \\ ing, Zhengzhou University, Zhengzhou 450001, Henan, China \\ ${ }^{\mathrm{b}}$ XJTU-Oxford International Joint Laboratory for Catalysis, School of Chemical Engineering and Technology, Xi'an Jiaotong University, Xi'an 710049, \\ Shaanxi, China
}

\section{A R T I C L E I N F O}

\section{Article history:}

Received 29 April 2020

Accepted 26 May 2020

Available online 5 September 2020

Keywords:

$\mathrm{SnS}_{2} / \mathrm{rGO} / \mathrm{TiO}_{2}$

Hollow sphere

Photocatalyst

Hole injection layer

Cr(VI) reduction

\begin{abstract}
A B S T R A C T
In this work, a hierarchical porous $\mathrm{SnS}_{2} / \mathrm{rGO} / \mathrm{TiO}_{2}$ hollow sphere heterojunction that allows highly-efficient light utilization and shortening distance of charge transformation is rationally designed and synthesized. More importantly, an rGO interlayer is successfully embedded between the $\mathrm{TiO}_{2}$ hollow sphere shells and outermost $\mathrm{SnS}_{2}$ nanosheets. This interlayer functions as a bridge to connect the two light-harvesting semiconductors and acts as a hole injection layer in the tandem heterojunction. The induced built-in electric fields on both sides of the interface precisely regulate the spatial separation and directional migration of the photo-generated holes from the light-harvesting semiconductor to the rGO hole injection interlayer. These synergistic effects greatly prolong the lifetime of the photo-induced charge carriers. The optimized tandem heterojunction with a $2 \mathrm{wt} \%$ rGO loading demonstrate enhanced visible-light-driven photocatalytic activity for Rhodamine B (RhB) dye degradation (removal rate: 97.3\%) and $\mathrm{Cr}(\mathrm{VI})$ reduction (removal rate: 97.09\%). This work reveals a new strategy for the rational design and assembly of hollow-structured photocatalytic materials with spatially separated reduction and oxidation surfaces to achieve excellent photocatalytic performance.
\end{abstract}

(C) 2021, Dalian Institute of Chemical Physics, Chinese Academy of Sciences. Published by Elsevier B.V. All rights reserved.

\section{Introduction}

Recently, water pollution caused by organic contaminants and heavy metals has posed a serious threat to human health, the ecosystem, and sustainable social development. Photocatalysis is considered to be an attractive potential strategy to solve these worsening environmental issues, due to its high efficiency, low cost, energy savings, and lack of secondary pollution [1-3]. Efficient light absorption, high charge separation, and fast surface reaction kinetics are requisite properties for high-performance photocatalysts [4-8]. In this respect, porous $\mathrm{TiO}_{2}$ hollow spheres are a promising candidate for the construction of systems with high photocatalytic activity, as they exhibit the following merits: (1) The raw material is inexpensive, non-toxic, and has a moderate redox potential and high thermal and chemical stability. (2) The hollow architecture not only adequately utilizes incident light through multiple light scattering, but also provides a large surface area that exposes

\footnotetext{
*Corresponding author. Tel/Fax: +86-29-82668658; E-mail: guidongyang@xjtu.edu.cn

This work was supported by the National Natural Science Foundation of China (U1862105), Key R\&D and Promotion Special Project (Science and Technology Research) of Henan Province (202102210053), China Postdoctoral Science Foundation (2019M662515) and K. C. Wong Education Foundation, Hong Kong, China.

DOI: 10.1016/S1872-2067(20)63649-X | http://www.sciencedirect.com/science/journal/18722067 | Chin. J. Catal., Vol. 42, No. 4, April 2021
} 
abundant active sites. (3) Their porosity provides additional channels to enable mass transfer processes [7-11]. Nevertheless, hollow-structured $\mathrm{TiO}_{2}$ presents the intrinsic drawbacks of narrow spectral absorption and inefficient separation and transport of photo-induced charge carriers, which significantly inhibits its practical applications [12-15].

Therefore, the design of broad-spectrum-responsive $\mathrm{TiO}_{2}$-based photocatalysts with good photocatalytic performance is important to achieve widespread and practical application. The construction of heterojunctions by coupling narrow-band-gap semiconductors has been demonstrated to be a powerful strategy to efficiently extend light absorption and promote charge separation. The indirect bandgap semiconductor $\mathrm{SnS}_{2}$ has many inherent advantages, such as its narrow bandgap $(E g=2.18-2.44 \mathrm{eV})$, low toxicity, excellent chemical stability, low cost, and wide spectral response [16-19]. Therefore, the combination of ultrathin $\mathrm{SnS}_{2}$ nanosheets with porous $\mathrm{TiO}_{2}$ hollow spheres should provide significant synergistic effects in terms of the photocatalytic performance of the heterojunction. The hierarchical hollow sphere structure is beneficial for visible light harvesting, while the ultrathin $\mathrm{SnS}_{2}$ nanosheets have a shorter charge-diffusion length, thus efficiently inhibiting the internal recombination of the photo-excited charge carriers. However, due to the limitations of their energy band positions, type-I band alignments are easily formed in $\mathrm{TiO}_{2} / \mathrm{SnS}_{2}$ composites, which reduces their photocatalytic redox ability to a large extent. Additionally, the surviving photo-generated electrons and holes accumulated on the surfaces of the components have a high probability of random surface recombination. To overcome these limitations, the creation of an interfacial driving force to regulate charge separation and transfer is urgently needed.

To overcome the above-mentioned problems, embedding reduced graphene oxide (rGO) at the interface between $\mathrm{TiO}_{2}$ and $\mathrm{SnS}_{2}$ is thought to be a promising approach to precisely control the photo-excited electron or hole extraction via the formation of built-in electric fields on both sides of the interface [20-22]. For instance, Li et al. [23] employed a partially oxidized graphene (pGO) layer as an interfacial conduction layer in a $\mathrm{CoPO}_{3} / \mathrm{pGO} / \mathrm{LDH} / \mathrm{BiVO}_{4}$ photoanode; the pGO layer was crucial in facilitating the transfer of photo-induced holes from $\mathrm{BiVO}_{4}$ to $\mathrm{CoPO}_{3}$. Dai et al. [22] have demonstrated that functionalized GO can act as an excellent hole-extraction material in heterojunctions to further improve device performance. Moreover, previous reports have indicated that the band structure, work function, conductivity, hydrophilicity, and optical properties of rGO can be readily tuned via chemical functionalization $[24,25]$. Thus, the use of different semiconductors with suitable energy levels on either side of rGO can effectively accelerate the spatial separation and directional migration of photo-induced charge carriers near the surface due to the potential gradients at the interfaces of the heterojunction.

Herein, we report the synthesis of a hierarchical porous $\mathrm{SnS}_{2} / \mathrm{rGO} / \mathrm{TiO}_{2}$ hollow sphere heterojunction via a modified "silica-protected calcination" method. The hierarchical porous hollow sphere structure not only enhances the light-harvesting ability of the composite, but also provides abundant active sites for the photoredox reaction. The rGO interlayer between the two light absorbers serves as an effective hole injection layer. The driving force derived from the built-in interfacial electric fields can effectively facilitate directional injection of the photo-induced holes from $\mathrm{TiO}_{2}$ and $\mathrm{SnS}_{2}$ to the $\mathrm{rGO}$ interlayer, thus retarding charge recombination. This special structural design spatially isolates the oxidation and reduction sites on the different materials, leading to a selective photoredox reaction surface. Compared to bare $\mathrm{TiO}_{2}, \mathrm{SnS}_{2}$, and binary $\mathrm{SnS}_{2} / \mathrm{TiO}_{2}$ composites, the optimal tandem heterojunction with a $2 \mathrm{wt} \%$ rGO loading exhibited significantly improved visible-light photocatalytic performance and durability in Rhodamine B (RhB) decomposition and $\mathrm{Cr}(\mathrm{VI})$ reduction.

\section{Experimental}

All chemicals were purchased from Sinopharm Chemical Reagent Co., Ltd., were of analytical grade, and were used as received. The experimental details are provided in the Supporting Information.

\subsection{Materials}

All chemicals were of analytical grade and used as received. Tetraethyl orthosilicate (TEOS), ethanol, $\mathrm{NH}_{3} \cdot \mathrm{H}_{2} \mathrm{O}, \mathrm{Ti}\left(\mathrm{OC}_{4} \mathrm{H}_{9}\right)_{4}$ (TBOT), acetonitrile, polyvinylpyrrolidone (PVP, K30), $\mathrm{NaOH}$, $\gamma$-aminopropyl methyl diethoxysilane (APTES), $\mathrm{SnCl}_{4} \cdot 5 \mathrm{H}_{2} \mathrm{O}$, L-cysteine, rhodamine $\mathrm{B}(\mathrm{RhB})$ and $\mathrm{K}_{2} \mathrm{Cr}_{2} \mathrm{O}_{7}$ were purchased from Sinopham Chemical Reagent Co., Ltd.

\subsection{Synthesis of $\mathrm{SiO}_{2}$ nanospheres}

$\mathrm{SiO}_{2}$ nanospheres were synthesized by the modified Stöber's method [1]. In a typical synthesis, $10 \mathrm{~mL} \mathrm{H} \mathrm{H}_{2} \mathrm{O}, 5 \mathrm{~mL} \mathrm{NH} \cdot \mathrm{H}_{2} \mathrm{O}$ (28 wt\%) and $50 \mathrm{~mL}$ ethanol were added into a conical flask. Then, $5 \mathrm{~mL}$ TEOS was slowly dropped into the mixed solution and magnetic stirred for $6 \mathrm{~h}$ at room temperature. After the reaction, $\mathrm{SiO}_{2}$ nanospheres were centrifuged and washed by deionized water and ethanol for three times, respectively. Then, $\mathrm{SiO}_{2}$ nanospheres were re-dispersed into $10 \mathrm{~mL}$ ethanol for further experiment.

\subsection{Synthesis of $\mathrm{TiO}_{2}$ hollow spheres}

The monodisperse $\mathrm{TiO}_{2}$ hollow spheres were prepared by using a modified silica-protected calcination method developed by Yin et al. In a typical synthesis, $1 \mathrm{~mL} \mathrm{SiO}_{2}$ nanosphere suspension was adding into the mixed solution containing $10 \mathrm{~mL}$ ethanol and $7 \mathrm{~mL}$ acetonitrile. After ultrasonication for $30 \mathrm{~min}$, the mixture containing $0.5 \mathrm{~mL}$ TBOT, $3 \mathrm{~mL}$ ethanol and $1 \mathrm{~mL}$ acetonitrile was rapidly injected into the aforementioned mixture under continuously stirring for $6 \mathrm{~h}$ at room temperature. The precipitate was centrifuged and washed with deionized water and ethanol for three times, respectively, re-dispersed into $10 \mathrm{~mL} \mathrm{H}_{2} \mathrm{O}$, and followed by adding $0.2 \mathrm{~g}$ PVP under continuously stirring for $12 \mathrm{~h}$. Subsequently, the suspension was centrifuged and re-dispersed into $20 \mathrm{~mL}$ ethanol to form the 
mixed solution. Then, $5 \mathrm{~mL} \mathrm{H} \mathrm{H}_{2} \mathrm{O}, 1 \mathrm{~mL} \mathrm{NH} \mathrm{H}_{3} \cdot \mathrm{H}_{2} \mathrm{O}(28 \mathrm{wt} \%)$ and 1 $\mathrm{mL}$ TEOS was successively added into the aforementioned mixture. After continuously magnetic stirring for $6 \mathrm{~h}$, the precipitate was centrifuged, washed and dried in a vacuum drying oven at $40{ }^{\circ} \mathrm{C}$ for $12 \mathrm{~h}$. The obtained product was directly calcined in air at $900{ }^{\circ} \mathrm{C}$ for $2 \mathrm{~h}$ with a heating rate of $2.5^{\circ} \mathrm{C} \cdot \mathrm{min}^{-1}$ to give the double-shell $\mathrm{SiO}_{2} / \mathrm{TiO}_{2} / \mathrm{SiO}_{2}$ nanospheres. After calcining, the obtained $\mathrm{SiO}_{2} / \mathrm{TiO}_{2} / \mathrm{SiO}_{2}$ nanospheres were etched with $20 \mathrm{~mL} \mathrm{NaOH}$ aqueous solution $\left(1 \mathrm{moL} \cdot \mathrm{L}^{-1}\right)$ at $90{ }^{\circ} \mathrm{C}$ for $4 \mathrm{~h}$ to produce porous $\mathrm{TiO}_{2}$ hollow spheres.

\subsection{Synthesis of hierarchical porous $\mathrm{SnS}_{2} / \mathrm{rGO}_{\mathrm{TiO}}$ hollow spheres}

The hierarchical porous $\mathrm{SnS}_{2} / \mathrm{rGO} / \mathrm{TiO}_{2}$ hollow spheres were fabricated by the multi-step method. The few-layered graphene oxide (GO) nanosheets were firstly fabricated from graphite flakes by the ultrasonic-assisted Hummers' method reported in our previous work [2]. Secondly, $0.4 \mathrm{~g}$ obtained $\mathrm{TiO}_{2}$ hollow spheres was dispersed into $1.6 \mathrm{~mL}$ APTES and 20 $\mathrm{mL}$ isopropanol under continuously magnetic stirring for 24 . The white suspension was centrifuged and washed by deionized water and ethanol several times, then dried in a vacuum drying oven at $60{ }^{\circ} \mathrm{C}$ for $12 \mathrm{~h}$. 0.0168 g surface-modified $\mathrm{TiO}_{2}$ hollow spheres and $0.0739 \mathrm{~g} \mathrm{SnCl}_{4} \cdot 5 \mathrm{H}_{2} \mathrm{O}$ were dispersed into certain concentration of GO aqueous solution under continuously magnetic stirring for $3 \mathrm{~h}$. Subsequently, $0.1939 \mathrm{~g}$ L-cysteine was dissolved in the mixed suspension. After magnetic stirring for $1 \mathrm{~h}$, the mixture solution was moved into a Teflon-lined steel autoclave and heated at $180^{\circ} \mathrm{C}$ for $2 \mathrm{~h}$. After being cooled to room temperature naturally, the products were centrifuged and washed thoroughly with deionized water and ethanol for three times, and dried under vacuum at $60^{\circ} \mathrm{C}$ for 12 h. The composites with different contents of GO nanosheets were prepared according to the same method. The $\mathrm{GO} / \mathrm{TiO}_{2}$ hollow spheres with $16.7 \mathrm{wt} \%, 12.5 \mathrm{wt} \%, 10 \mathrm{wt} \%$ and $2 \mathrm{wt} \%$ GO nanosheets loading were named as TG-1, TG-2, TG-3 and TG-4 composites, and the corresponding as-prepared hierarchical $\mathrm{SnS}_{2} / \mathrm{rGO} / \mathrm{TiO}_{2}$ hollow spheres were denoted as TGS-1, TGS-2, TGS-3 and TGS-4 composites, respectively. For comparison, the binary $\mathrm{SnS}_{2} / \mathrm{TiO}_{2}$ hollow spheres with different molar ratios were also prepared by the similar procedure, except that GO nanosheets were omitted. And the as-prepared samples with molar ratios of Ti/Sn in 1:2, 1:1 and 2:1 were denoted as TS-1, TS- 2 and TS-3 composites.

\subsection{Characterization}

The X-ray diffraction (XRD) patterns were carried out by a Lab X XRD-6100 X-ray diffractometer with $\mathrm{Cu} K_{\alpha}$ radiation $(\lambda=$ $1.5418 \AA$ A). Field-emission scanning electron microscope (FE-SEM, FEI Quanta F250, $200 \mathrm{KV}$ ) and transmission electron microscopy (TEM; JEOL, JEM-2100) coupled with X-ray energy dispersive spectrometer (EDS) analysis were performed to investigate the structure, size and morphology in the as-prepared samples. The surface states, chemical composition and energy level structure of photocatalysts were characterized by an AXIS Supra X-ray photoelectron spectroscopy (XPS), which equipped with an ultraviolet photoelectron spectrometer (UPS). The specific surface area and pore size distribution measured with the BET analyzer (BELSORP-Max, MicrotracBEL) were analyzed by the Brunauer-Emmett-Teller (BET) and Barrett-Joyner-Halenda (BJH) methods, respectively. The optical property tests were performed with a UV-2600 UV-vis spectrophotometer ( $\mathrm{SHIMADZU}$ ), using $\mathrm{BaSO}_{4}$ as the reference. A FLS980 fluorescence spectrophotometer (Edinburgh Instruments; $\lambda_{\mathrm{ex}}=325 \mathrm{~nm}$ ) was used to record the photoluminescence (PL) spectra. Fourier transform infrared spectra (FT-IR) and Raman spectra were obtained by a Nicolet iS50 spectrophotometer (ThermoFisher) and a LabRAM HR800 laser Raman spectrometer (HORIBA; $\lambda_{\mathrm{ex}}=633 \mathrm{~nm}$ ), respectively.

\subsection{Photoelectrochemical and electrochemical measurements}

The dates of transient photocurrent density, electrochemical impedance spectra (EIS) and Mott-Schottky plots were collected on a CHI 660D electrochemical workstation using a conventional three-electrode cell system. Typically, the working electrodes were prepared as follows: $3 \mathrm{mg}$ of as-prepared photocatalysts were dispersed into the mixed solution, including: 1 $\mathrm{mL}$ ultrapure water, $0.5 \mathrm{~mL}$ isopropanol and $50 \mu \mathrm{L}$ perfluorosulfonic acid polymer (Nafion). Then $50 \mu \mathrm{L}$ of the resultant slurry was coated onto the surface of the cleaned glassy carbon electrode (effective area: $0.076 \mathrm{~cm}^{2}$ ) and dried at room temperature overnight to form uniform film electrodes. Under ambient temperature $\left(25^{\circ} \mathrm{C}\right)$, the transient photocurrent response was performed on the electrochemical analyzer under irradiation by a $300 \mathrm{~W}$ xenon lamp ( $\geq 420 \mathrm{~nm}$ ), which positioned $10 \mathrm{~cm}$ far from the surface of the working electrode. Meanwhile, a platinum gauze electrode and a $\mathrm{Ag} / \mathrm{AgCl}$ electrode were served as the counter electrode and reference electrode, respectively. $100 \mathrm{~mL} 1 \mathrm{M} \mathrm{Na}_{2} \mathrm{SO}_{4}$ aqueous solution in a quartz cell was used as the electrolyte solution. The electrochemical impedance spectra (EIS) were also performed in an electrolyte containing $1 \mathrm{M} \mathrm{Na}_{2} \mathrm{SO}_{4}$ aqueous solution at frequency range from $0.01 \mathrm{~Hz}$ to $100 \mathrm{kHz}$ (AC voltage of $5 \mathrm{mV}$ amplitude) under ambient temperature. Moreover, the Mott-Schottky plots of the as-prepared samples were measured in $0.5 \mathrm{moL} \cdot \mathrm{L}^{-1}$ of $\mathrm{Na}_{2} \mathrm{SO}_{4}$ electrolyte at a frequency of $1 \mathrm{kHz}$. The difference is that the saturated calomel electrode is chosen as the reference electrode. It should be noted that sunless conditions were ensured when EIS and Mott-Schottky experiments were carried out.

\subsection{Photocatalytic activity measurement}

The photocatalytic performance of the as-prepared photocatalysts was evaluated by photodegradation of $20 \mathrm{mg} \cdot \mathrm{L}^{-1} \mathrm{RhB}$ aqueous solution and photoreduction of $100 \mathrm{mg} \cdot \mathrm{L}^{-1} \mathrm{~K}_{2} \mathrm{Cr}_{2} \mathrm{O}_{7}$ aqueous solution under visible light irradiation, respectively. In general, $70 \mathrm{mg}$ of the as-fabricated photocatalysts were suspended into a specially designed photochemical reactor, which containing $70 \mathrm{~mL}$ of the aforementioned organic dye or $\mathrm{Cr}(\mathrm{VI})$ aqueous solution. It should be noted that the photocatalytic 
$\mathrm{Cr}(\mathrm{VI})$ photoreduction over different samples was carried out in the presence of tartaric acid (hole scavenger). Before light irradiation, the mixtures were magnetically stirred in the dark for $1 \mathrm{~h}$ to establish adsorption-desorption equilibrium between the photocatalysts and the corresponding pollutants. A $300 \mathrm{~W}$ Xe lamp (PLS-SXE300, Beijing perfectlight technology co. Ltd) equipped with a cut-off filter $(\lambda>420 \mathrm{~nm})$ was used as light source. During the visible light irradiation, $3 \mathrm{~mL}$ of the suspension was taken out at the given time intervals and centrifuged to remove the photocatalyst. At last, the supernatant solution was analyzed by a UV-2600 UV-vis spectrophotometer (SHIMADZU) at the corresponding characteristic absorption peaks (RhB at $553 \mathrm{~nm}, \mathrm{Cr}(\mathrm{VI})$ at $350 \mathrm{~nm}$ ). The recycling tests over the photocatalysts were carried out as the similar methods. The free radical scavenge experiments procedure was the same as that under the visible light, except the presence of different scavengers.

\section{Results and discussion}

\subsection{Morphological and structural characterization}

The overall procedure for the synthesis of the hierarchical porous $\mathrm{SnS}_{2} / \mathrm{rGO} / \mathrm{TiO}_{2}$ hollow spheres is shown in Scheme 1 . Uniform $\mathrm{SiO}_{2}$ nanospheres were selected as a hard template. First, the $\mathrm{TiO}_{2}$ precursor was coated on the surface of the $\mathrm{SiO}_{2}$ nanospheres in-situ in the presence of the surfactant polyvinyl pyrrolidone (PVP). Subsequently, a silica layer was applied on the external surface of the $\mathrm{TiO}_{2}$ precursor. This modified "silica-protected calcination" process is a vital step for inducing the crystallization of the amorphous $\mathrm{TiO}_{2}$ to the anatase phase while avoiding nanocrystal coalescence and further phase transition under the high temperature calcination conditions [26]. Transmission electron microscopy (TEM) images (Fig. S1) show that the thicknesses of the $\mathrm{TiO}_{2}$ interlayer and the outermost $\mathrm{SiO}_{2}$ shell in the obtained well-defined double-shelled $\mathrm{SiO}_{2} / \mathrm{TiO}_{2} / \mathrm{SiO}_{2}$ microspheres were approximately 100 and 73 nm, respectively. The $\mathrm{SiO}_{2}$ core and protective layer were removed simultaneously by alkali etching to give the porous $\mathrm{TiO}_{2}$ hollow spheres. Scanning electron microscopy (SEM) (Fig. 1(a)) and TEM images (Figs. 1(b) and (c)) clearly reveal that the ob-

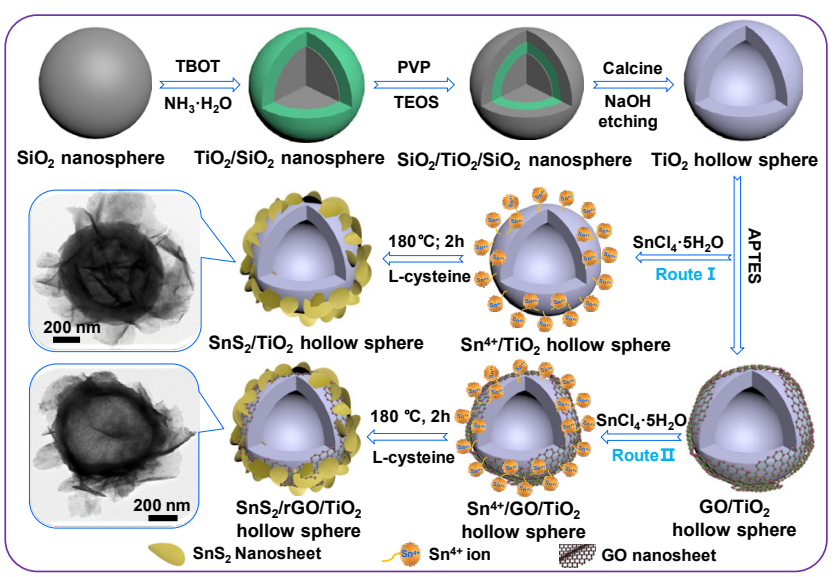

Scheme 1. Schematic illustration of the synthetic procedure of the hierarchical porous $\mathrm{SnS}_{2} / \mathrm{rGO} / \mathrm{TiO}_{2}$ hollow spheres. tained $\mathrm{TiO}_{2}$ exhibited a monodisperse hollow spherical structure with diameters of 687-720 $\mathrm{nm}$. The hollow structure was further confirmed by the broken shell observed in Fig. 1(a). Notably, the use of PVP and the protective layer were necessary in order to provide a porous structure and prevent the coalescence of the $\mathrm{TiO}_{2}$ shells during synthesis. Subsequent surface modification of $\mathrm{TiO}_{2}$ using aminopropyl triethoxysilane (APTES) was carried out to facilitate the coupling of the GO nanosheets (Fig. S2) on the positively charged $\mathrm{TiO}_{2}$ surface via electrostatic interactions. Even when the loading amount of GO was reduced from $16.7 \mathrm{wt} \%$ to $2 \mathrm{wt} \%$, SEM (Fig. S3 and Fig. 1(d)), TEM (Fig. 1(e)), and high resolution transmission electron microscopy (HRTEM) (Fig. 1(f)) images of the $\mathrm{GO} / \mathrm{TiO}_{2}$ composites clearly indicated that the surfaces of the $\mathrm{TiO}_{2}$ shells were wrapped with ultrathin GO nanosheets, resulting a wrinkled, rough surface. The observed lattice fringe spacing of 0.243 $\mathrm{nm}$ corresponded to the (103) facet of anatase $\mathrm{TiO}_{2}$. Finally, hierarchical porous $\mathrm{SnS}_{2} / \mathrm{rGO} / \mathrm{TiO}_{2}$ hollow spheres were obtained via the hydrothermal method. For comparison, binary $\mathrm{SnS}_{2} / \mathrm{TiO}_{2}$ composites were also synthesized using this method.

The structures of the as-prepared photocatalysts were probed using SEM and TEM. When a Ti/Sn molar ratio of 1:1 was used, an appropriate amount of $\mathrm{SnS}_{2}$ nanosheets were anchored vertically on the surface of $\mathrm{TiO}_{2}$ to form a binary $\mathrm{SnS}_{2} / \mathrm{TiO}_{2}$ hollow sphere heterojunction (denoted as TS-2; Figs. S4(c) and (d)). As shown in Figs. S4(a) and (b) (denoted as TS-1), and Figs. S4(e) and (f) (denoted as TS-3), further increasing or decreasing the molar ratio of $\mathrm{Ti} / \mathrm{Sn}$ resulted in excessive or inadequate coating of $\mathrm{SnS}_{2}$ nanosheets on the surface of the $\mathrm{TiO}_{2}$ shells, respectively. After the introduction of GO, the as-prepared ternary $\mathrm{SnS}_{2} / \mathrm{rGO} / \mathrm{TiO}_{2}$ composites with a $2 \mathrm{wt} \%$ GO loading (denoted as composite TGS-4; Figs. 2(a)-(c)) exhibited a spherical morphology similar to that of the TS-2 composite. Energy dispersive X-ray (EDX) elemental mapping images of the TGS-4 composite (Figs. 2(e)-(i)) confirmed that the $\mathrm{TiO}_{2}$ hollow spheres were encapsulated by rGO nanosheets. Additionally, the elements $\mathrm{S}$ and $\mathrm{Sn}$ were both distributed uniformly over the surface of the rGO, indicating the construction of a well-defined hierarchical $\mathrm{SnS}_{2} / \mathrm{rGO} / \mathrm{TiO}_{2}$ hollow sphere heterojunction.

The selected-area electron diffraction (SAED) patterns of both the TS-2 (inset in Fig. S5(a)) and TGS-4 (Fig. 2(j)) compo-

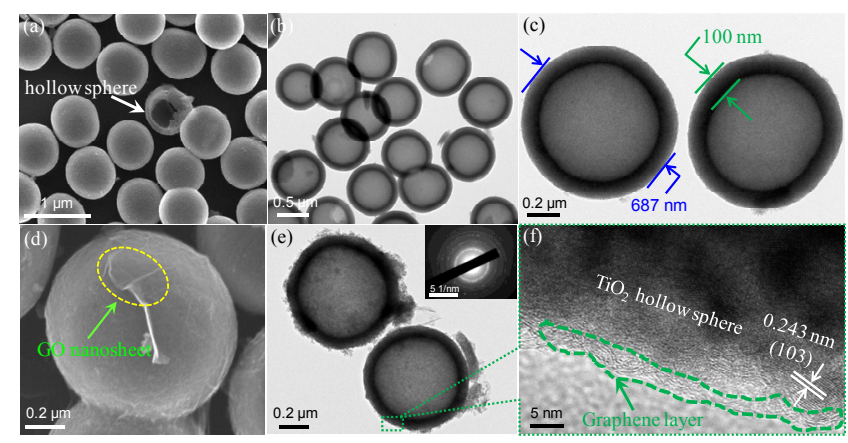

Fig. 1. SEM (a), TEM (b), and HRTEM (c) images of $\mathrm{TiO}_{2}$ hollow spheres; SEM (d), TEM (e), and HRTEM (f) images (inset of (e) is the corresponding SAED pattern) of $\mathrm{GO} / \mathrm{TiO}_{2}$ composite (TG-4; 2 wt\% GO loading). 


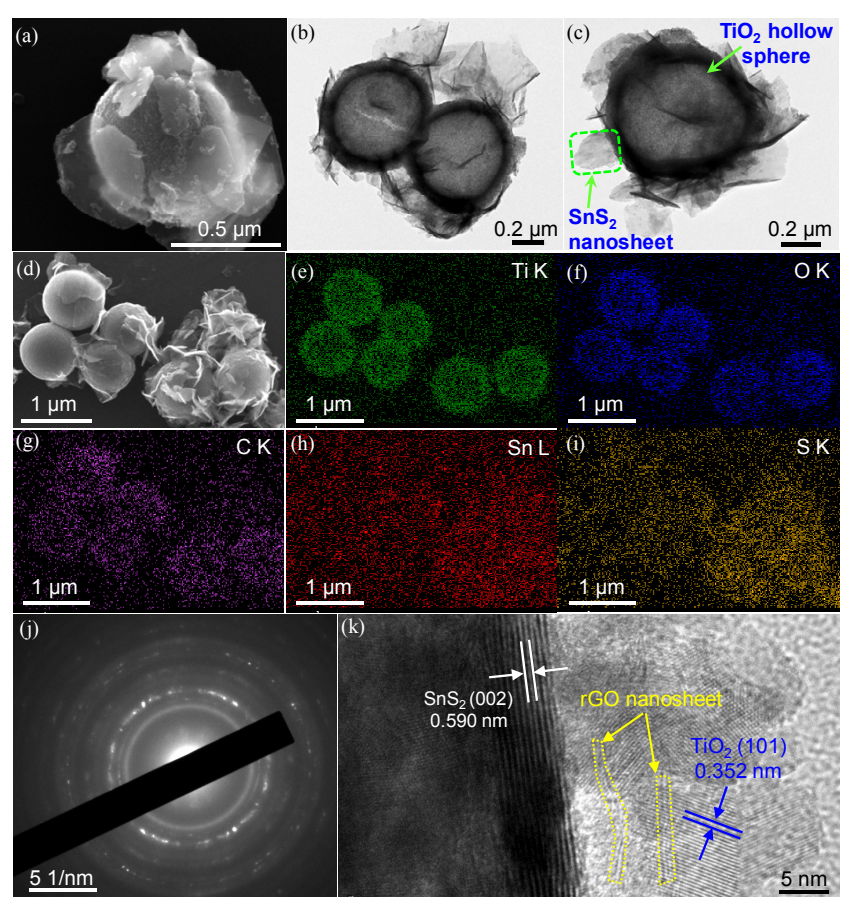

Fig. 2. $\mathrm{SnS}_{2} / \mathrm{rGO} / \mathrm{TiO}_{2}$ composite with $2 \mathrm{wt} \%$ GO loading (TGS-4 composite): (a,d) SEM and $(b, c)$ TEM images. EDS elemental mapping images of a selected area: (e) Ti, (f) O, (g) C, (h) Sn, and (i) S. (j) Corresponding SAED pattern and (k) HRTEM image.

sites suggested that these composites exhibited a polycrystalline structure. The corresponding HRTEM images in Fig. 2(k) and Fig. S5(c) show lattice fringes with interplanar spacings of 0.352 and $0.590 \mathrm{~nm}$, which correspond to the (101) plane of anatase $\mathrm{TiO}_{2}$ (JCPDS no. 21-1272) and the (002) plane of hexagonal $\mathrm{SnS}_{2}$ (JCPDS no. 21-1231), respectively. In contrast to the TS- 2 composite, the TGS-4 composite clearly shows a structure in which the dual catalysts $\mathrm{TiO}_{2}$ and $\mathrm{SnS}_{2}$ are spatially separated by the few-layered rGO interlayer. The intimate contact at the material interfaces is beneficial in terms of providing charge transfer pathways to achieve the spatial separation and rapid transport of the photo-induced charge carriers during the photoredox reaction [27-29].

The crystalline features and surface chemical compositions of the as-obtained samples were characterized in further detail using X-ray diffraction (XRD) patterns and X-ray photoelectron spectroscopy (XPS). As shown in Fig. 3(a), the main diffraction peaks at $25.28^{\circ}, 37.80^{\circ}, 48.05^{\circ}$, and $62.69^{\circ}$ were indexed to the (101), (004), (200), and (204) planes of anatase $\mathrm{TiO}_{2}$ (JCPDS no. 21-1272), respectively. Only one diffraction peak at $54.32^{\circ}$ was assigned to rutile $\mathrm{TiO}_{2}$ (JCPDS no. 21-1276). This further confirmed that phase transition and agglomeration during high temperature calcination $\left(900{ }^{\circ} \mathrm{C}\right)$ were effectively prevented via the modified "silica-protected calcination" strategy. Additionally, peaks characteristic of hexagonal $\mathrm{SnS}_{2}$ crystals were located at $15.00^{\circ}, 28.22^{\circ}, 29.26^{\circ}, 41.99^{\circ}, 50.08^{\circ}$, and $52.55^{\circ}$ (JCPDS no. 21-1231), respectively. The resulting TS-2 and TGS-4 composites demonstrated good crystallinity and purity, in agreement with the HR-TEM observations. The two characteristic peaks at 1332.6 and $1582.3 \mathrm{~cm}^{-1}$ in the Raman spectra
(Fig. 3(b)) were assigned to the D and G bands of graphene $[30,31]$. The mean intensity ratio between the $D$ and $G$ bands $\left(I_{\mathrm{D}} / I_{\mathrm{G}}\right)$ in the TGS-4 composite was 1.26 , which was slightly larger than that of the $\mathrm{GO} / \mathrm{TiO}_{2}$ composite. Additionally, the weak 2D $\left(2620 \mathrm{~cm}^{-1}\right)$ and $2 \mathrm{G}\left(2894 \mathrm{~cm}^{-1}\right)$ peaks further confirmed the few-layered structure of the graphene [32,33]. As can be seen from the FT-IR spectra in Fig. S6, the intensities of the peaks corresponding to oxygen-containing functional groups in the TGS-4 composite were obviously lower than in the $\mathrm{GO} / \mathrm{TiO}_{2}$ composite. These results not only demonstrated the partial conversion of GO into rGO, but also confirmed the existence of additional structural defects originating from the coupling between the rGO interlayer and the $\mathrm{SnS}_{2} / \mathrm{TiO}_{2}$ composite $[34,35]$.

The survey XPS spectrum of the TGS-4 composite (Fig. 3(c)) clearly exhibited strong C $1 s, 01 s$, Ti $2 p, \mathrm{~S} 2 p$, and Sn $3 d$ signals, further confirming the existence of $\mathrm{rGO}, \mathrm{SnS}_{2}$, and $\mathrm{TiO}_{2}$ in the composite. The peaks at binding energies of 284.8, 286.7, 287.8, and $288.9 \mathrm{eV}$ in the $\mathrm{C} 1 \mathrm{~s}$ XPS spectrum of GO (Fig. 3(d)) were highly consistent with $\mathrm{C}-\mathrm{C}, \mathrm{C}-\mathrm{O}, \mathrm{C}=\mathrm{O}$, and $\mathrm{O}-\mathrm{C}=0$ groups, respectively. The disappearance of the $\mathrm{C}=0$ peak $(287.8 \mathrm{eV})$ in the TGS-4 composite reflects the fact that GO was reduced to some extent by the removal of some of the oxygen-containing functional groups during the hydrothermal treatment $[32,36]$. The three peaks in the $01 s$ XPS spectrum of the TGS-4 composite (Fig. 3(e)) centered at 530.6, 531.9, and 533.4 eV were attributed to hydroxyl groups adsorbed on the surface of $\mathrm{TiO}_{2}$ and the $\mathrm{O}-\mathrm{C}=\mathrm{O}$ and $\mathrm{C}=\mathrm{O}$ species of $\mathrm{rGO}$, respectively. However, the $01 \mathrm{~s}$ XPS spectrum of $\mathrm{TiO}_{2}$ can be deconvoluted into four individual peaks located at 529.4, 530.5, 531.8, and $533.3 \mathrm{eV}$. The new peak centered at $529.4 \mathrm{eV}$ was attributed to the lattice oxygen (Ti-O-Ti) of $\mathrm{TiO}_{2}[32,37,38]$. In the TGS- 4 composite, the two prominent peaks centered at 459.2 and $464.9 \mathrm{eV}$ in the high-resolution Ti $2 p$ spectrum (Fig. 3(f)) were assigned as the Ti $2 p_{3 / 2}$ and $\mathrm{Ti} 2 p_{1 / 2}$ peaks of the $\mathrm{Ti}^{4+}$ of $\mathrm{TiO}_{2}$, respectively. As shown in Fig. 3(g), the S $2 p$ XPS spectrum can be fitted into four discernible peaks. The two spin-orbit doublets located at 161.8 and $162.9 \mathrm{eV}$ were assigned as the $\mathrm{S} 2 p_{3 / 2}$ and $\mathrm{S} 2 p_{1 / 2}$ peaks of the $\mathrm{S}^{2-}$ of metal sulfide [31]. The second doublet at 163.5 and $164.6 \mathrm{eV}$ corresponded to the $\mathrm{S} 2 p_{3 / 2}$ and $\mathrm{S} 2 p_{1 / 2}$ states of polysulfide, respectively [31,39]. The high-resolution XPS spectrum of Sn $3 d$ can be resolved into two peaks centered at 486.9 and $495.3 \mathrm{eV}$, corresponding to $\mathrm{Sn} 3 d_{5 / 2}$ and $\mathrm{Sn} 3 d_{3 / 2}$, respectively. Notably, the binding energies of $01 s$ and Ti $2 p$ in the TGS-4 sample were shifted to slightly higher binding energies by 0.1 and $1.1 \mathrm{eV}$, respectively, compared with those of pure $\mathrm{TiO}_{2}$. In contrast, negative binding energy shifts of approximately 0.4 and $0.7 \mathrm{eV}$ relative to the pristine $\mathrm{SnS}_{2}$ spectrum were observed for S $2 p$ and Sn $3 d$ in the TGS- 4 sample, respectively. This behavior was attributed to the strong interactions at the interfaces between $\mathrm{TiO}_{2} / \mathrm{SnS}_{2}$ and the rGO interlayer. The XPS results further indicated that the resulting $\mathrm{SnS}_{2} / \mathrm{rGO} / \mathrm{TiO}_{2}$ heterojunction provided charge transfer channels for the spatial separation and rapid migration of photo-induced excited charge carriers.

\subsection{Photocatalytic activity and stability}




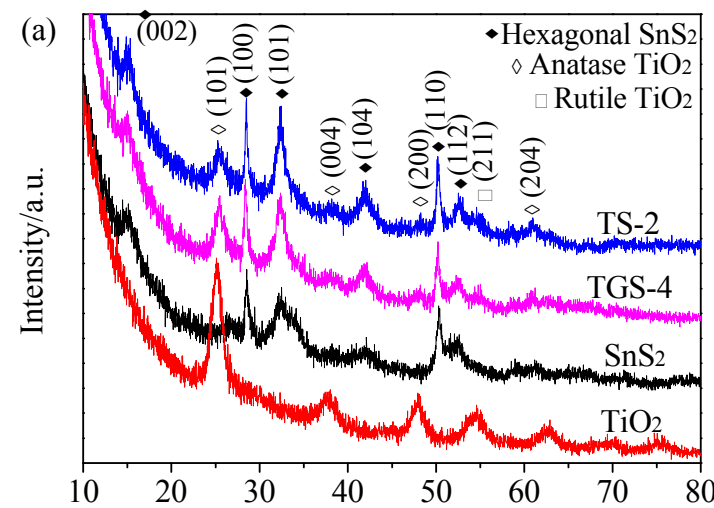

$2 \theta /\left({ }^{\circ}\right)$
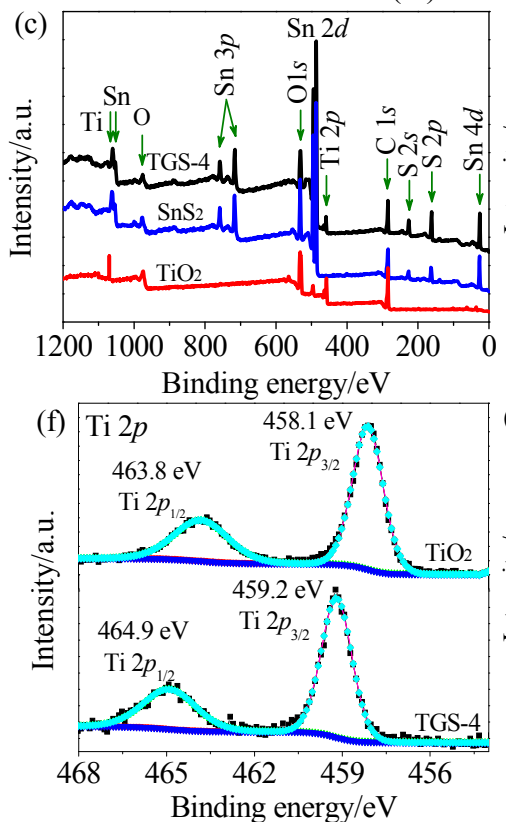

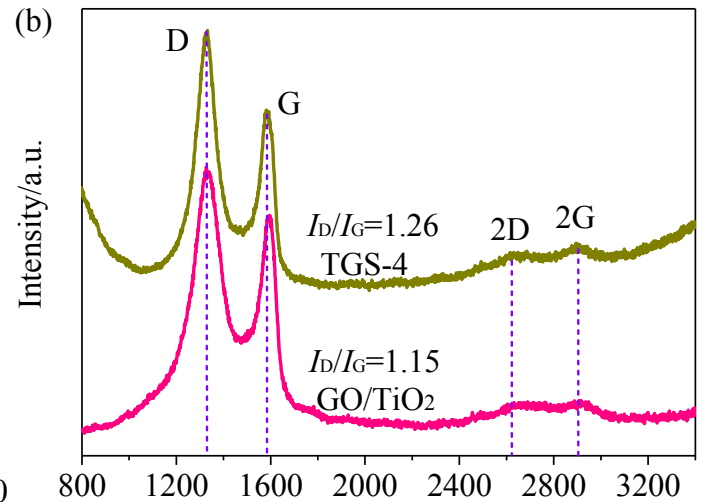

Raman shift $/ \mathrm{cm}^{-1}$
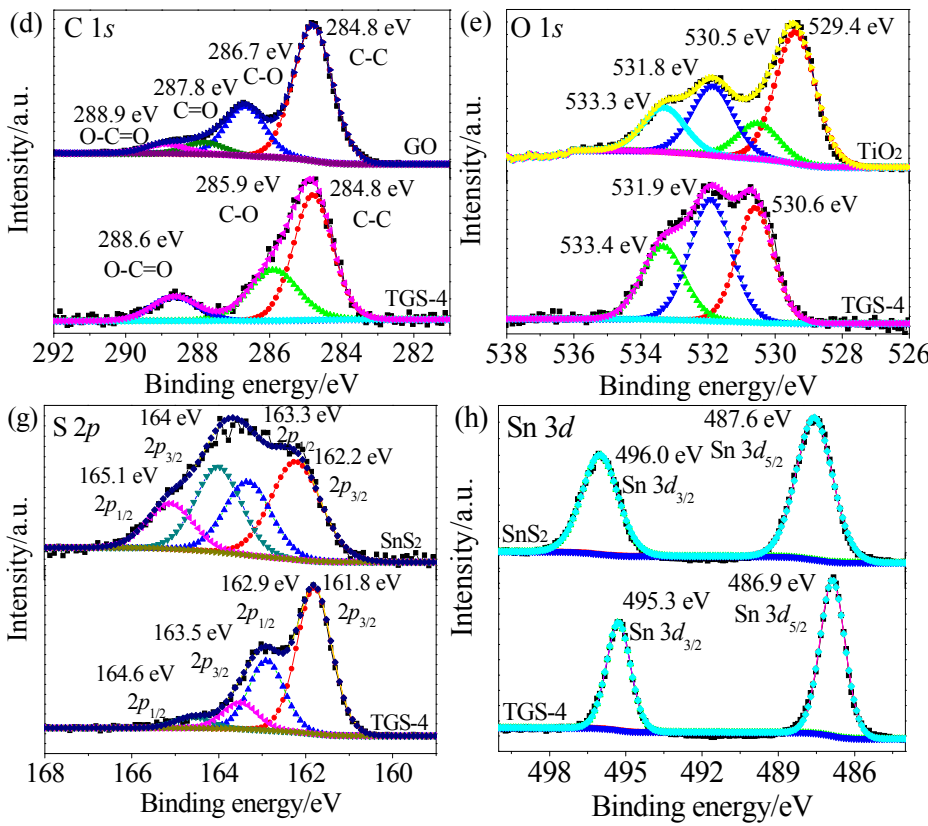

Fig. 3. XRD patterns (a) and Raman spectra (b) of the as-prepared samples obtained using an excitation wavelength of 633 nm; XPS survey spectrum (c) and high-resolution XPS spectra of the C $1 s(\mathrm{~d}), 01 s(\mathrm{e}), \mathrm{Ti} 2 p(\mathrm{f}), \mathrm{S} 2 p(\mathrm{~g})$, and Sn $3 d(\mathrm{~h})$ core levels of the different samples.

The visible-light photodegradation of the model contaminant RhB over different samples was then investigated. Prior to light irradiation, the photocatalytic system was continuously stirred in the dark for $60 \mathrm{~min}$ to ensure the establishment of the adsorption-desorption equilibrium (Fig. S7). As shown in Fig. 4(a), almost no RhB photodegradation occurred over the pure $\mathrm{TiO}_{2}$ due to the rapid recombination of the photo-induced charge carriers [36]. In contrast, the pristine $\mathrm{SnS}_{2}$ demonstrated a $75.2 \% \mathrm{RhB}$ removal rate under visible light irradiation for 140 min, which was significantly higher than that of the TS-2 composite (about 59.1\%). The TGS-4 composite showed the highest photocatalytic removal rate of $90.7 \%$. As the GO content of the composite was increased, the resulting $\mathrm{SnS}_{2} / \mathrm{rGO} / \mathrm{TiO}_{2}$ composites showed decreased photocatalytic performance in the removal of $\mathrm{RhB}$. This result indicated that the introduction of an optimal amount of rGO between $\mathrm{TiO}_{2}$ and $\mathrm{SnS}_{2}$ is beneficial to the separation of the photo-induced charge carriers. As shown in Fig. 4(b), 88.6\% RhB removal was observed over the TGS-4 composite after six consecutive cycles, indicating its high stability.
The photocatalytic activities of the different samples were also assessed by the visible-light-driven photoreduction of $\mathrm{Cr}(\mathrm{VI})$ in the presence of tartaric acid (a hole scavenger). As illustrated in Fig. 4(c), a $100 \mathrm{mg} \cdot \mathrm{L}^{-1} \mathrm{~K}_{2} \mathrm{Cr}_{2} \mathrm{O}_{7}$ aqueous solution maintained good stability both in the absence of the catalysts and in the presence of tartaric acid alone. Pure $\mathrm{TiO}_{2}$ exhibited a $31.8 \%$ removal rate in $\mathrm{Cr}(\mathrm{VI})$ reduction due to the fact that the photo-generated holes accumulated in the $\mathrm{VB}$ of $\mathrm{TiO}_{2}$ could be directly quenched by the hole scavenger tartaric acid. Thus, the presence of the hole scavenger prolonged the lifetime of the photo-induced charge carriers. After embedding the rGO interlayer, the optimized TGS-4 composite displayed the highest photocatalytic reduction performance, with a $97.1 \%$ removal rate; those of $\mathrm{SnS}_{2}$ and the TS-2 composite were $90.1 \%$ and $85.2 \%$, respectively. More interestingly, the photocatalytic reduction activity of the ternary $\mathrm{SnS}_{2} / \mathrm{rGO} / \mathrm{TiO}_{2}$ heterojunction gradually increased with decreasing $\mathrm{rGO}$ content. According to the results of a cyclic experiment (Fig. 4(d)), the removal efficiency of $\mathrm{Cr}(\mathrm{VI})$ over the TGS-4 composite was as high as $91.78 \%$ after six runs, confirming the high stability of the ter- 

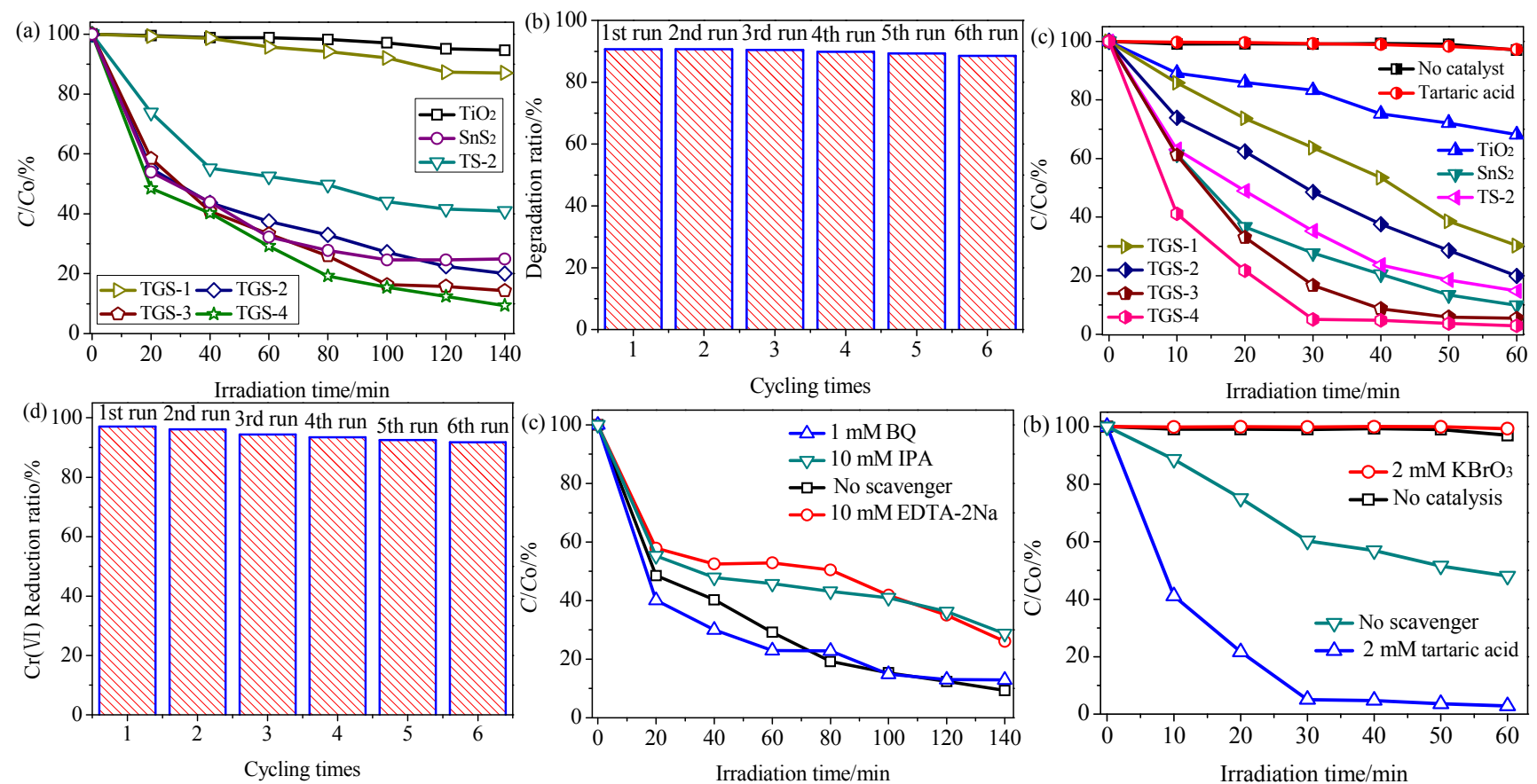

Fig. 4. Plots of RhB degradation (a) and $\mathrm{Cr}(\mathrm{VI})$ reduction (c); Cycling experiment results for the degradation of RhB (b) and reduction of Cr(VI) (d) over the TGS-4 composite; Plots of RhB degradation (e) and Cr(VI) reduction (f) over the TGS-4 composite in the presence of different scavengers. $\left(C_{\mathrm{RhB}}=20 \mathrm{mg} \mathrm{L}^{-1} ; C_{\mathrm{K} 2 \mathrm{Cr} 207}=100 \mathrm{mg} \cdot \mathrm{L}^{-1}\right)$.

nary $\mathrm{SnS}_{2} / \mathrm{rGO} / \mathrm{TiO}_{2}$ heterojunction.

Furthermore, radical trapping experiments were carried out to identify the main active species involved in the photoredox reaction. Based on the photodegradation plots shown in Fig. 4(e), after $140 \mathrm{~min}$ of visible light irradiation, the photodegradation efficiencies of $\mathrm{RhB}$ were $87.1 \%$ and $90.7 \%$ in the presence of benzoquinone $\left(\mathrm{BQ}\right.$, a superoxide radical $\left(\mathrm{O}^{2-} \bullet\right)$ scavenger) and in the absence of any scavenger, respectively. Only $73.9 \%$ and $71.3 \%$ of $\mathrm{RhB}$ were removed in the presence of ethylenediamine tetraacetic acid disodium salt (EDTA-2Na, a hole $\left(\mathrm{h}^{+}\right)$scavenger) and isopropanol (IPA, a hydroxyl radical $(\bullet \mathrm{OH})$ scavenger), respectively, at the same illumination time. This behavior suggests that photo-excited holes and $\bullet \mathrm{OH}$ species are the dominant reactive species in the photodegradation reaction [40]. Similar inhibition phenomena were observed during the photocatalytic reduction of $\mathrm{Cr}(\mathrm{VI})$. As shown in Fig. 4(f), the concentration of $\mathrm{Cr}(\mathrm{VI})$ remained unchanged in the presence of potassium bromate $\left(\mathrm{KBrO}_{3}\right.$, an electron (e-) scavenger) and in the absence of any photocatalysts. However, the reduction ratio of $\mathrm{Cr}(\mathrm{VI})$ over the TGS-4 composite in the presence of tartaric acid (a $\mathrm{h}^{+}$scavenger) was approximately $97.1 \%$, which was higher than in the control trial (52\%, no scavenger). The greatly improved photocatalytic activity indicated that the photo-excited electrons played a dominant role in $\mathrm{Cr}(\mathrm{VI})$ photoreduction.

\subsection{Nitrogen adsorption-desorption, optical and photoelectrochemical properties, ultraviolet photoelectron spectra, and Mott-Schottky plot analysis}

Generally, the construction of hollow structural photocatalysts with a large specific surface area provides a greater num- ber of active sites. As shown in Figs. 5(a) and (b), the $\mathrm{N}_{2}$ adsorption-desorption isotherms of both the $\mathrm{TiO}_{2}$ hollow sphere and TGS-4 samples can be classified as type IV hysteresis curves, indicating their mesoporous structure. The distinct slit-shaped hysteresis loops were assigned as typical type 3 hysteresis, indicating that the mesoporous structure originated from the accumulation of massive nanoparticles. The presence of large amounts of mesopores would facilitate the mass transfer process of the reactants during the photoredox reaction process [41]. Notably, the TGS-4 composite exhibited a Brunauer-Emmett-Teller (BET) specific surface area of $81.7 \mathrm{~m}^{2}$ $\mathrm{g}^{-1}$, which was significantly lower than that of the pure $\mathrm{TiO}_{2}$ hollow spheres $\left(208.3 \mathrm{~m}^{2} \mathrm{~g}^{-1}\right)$. The Barrett-Joyner-Halenda (BJH) pore sizes of the TGS-4 composite were mainly distributed in the 1.5-3 nm range (inset in Fig. 5(b)), which was narrower than that of pure $\mathrm{TiO}_{2}(3-13 \mathrm{~nm}$; inset in Fig. 5(a)). The decreased specific surface area and pore diameter of the TGS-4 composite were probably due to the wrapping of rGO and $\mathrm{SnS}_{2}$ nanosheets on the surface of $\mathrm{TiO}_{2}$. These results indicate that changes in the specific surface area and pore size distribution were not dominant factors responsible for the significantly enhanced photocatalytic activity of the as-prepared hierarchical porous $\mathrm{SnS}_{2} / \mathrm{rGO} / \mathrm{TiO}_{2}$ hollow sphere heterojunctions.

As shown in the UV-vis diffuse reflection (DRS) spectra in Fig. 5(c), the pure $\mathrm{TiO}_{2}$ displayed an optical absorption edge at $387 \mathrm{~nm}$. In contrast, the pristine $\mathrm{SnS}_{2}$ exhibited a wide absorption edge at $598.5 \mathrm{~nm}$. The coupling between $\mathrm{TiO}_{2}$ and $\mathrm{SnS}_{2}$ led to slightly decreased light absorption. The absorption edge of the as-obtained TS- 2 composite was determined to be about $575.5 \mathrm{~nm}$. The light absorption edge of the TGS-4 composite was observed at $548.7 \mathrm{~nm}$, which clearly represented a broadened light absorption range compared to that of $\mathrm{TiO}_{2}$. This 

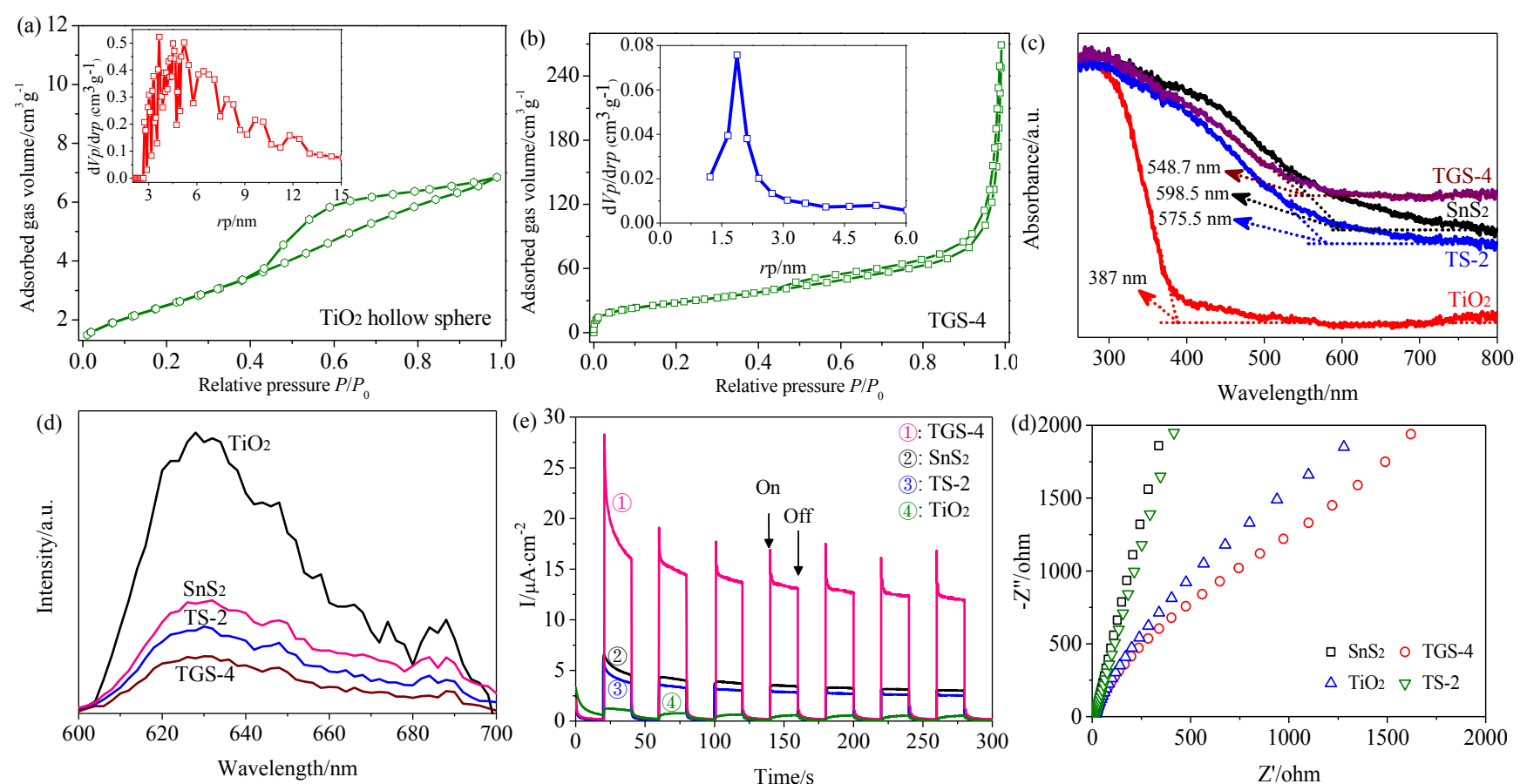

Fig. 5. $\mathrm{N}_{2}$ adsorption-desorption isotherms of $\mathrm{TiO}_{2}$ (a) and the TGS-4 composite (b); (c) UV-vis DRS spectra; (d) PL spectra excited at 325 nm; Transient photocurrent responses (e) and Nyquist plots (f) for the as-synthesized samples. The insets in (a) and (b) are the corresponding pore-size distribution curves.

redshift of the optical absorption of TGS-4 composite is beneficial in terms of visible light utilization [41]. Furthermore, the band gap of the semiconductor can be estimated from the absorption edges [32,41]. The bandgap energy of $\mathrm{SnS}_{2}$ was estimated to be $2.07 \mathrm{eV}$, which is slightly smaller than those of the TGS-4 composite $(2.26 \mathrm{eV})$ and pure $\mathrm{TiO}_{2}(3.2 \mathrm{eV})$, respectively. Although a smaller band gap means that electron-hole pairs can more easily be generated under light illumination, the TGS-4 composite exhibited a higher level of activity in $\mathrm{Cr}(\mathrm{VI})$ reduction and $\mathrm{RhB}$ degradation than pure $\mathrm{SnS}_{2}$, indicating that the construction of a heterojunction at both sides of the rGO interlayer was beneficial to the rapid migration and spatial separation of the photo-generated carriers, and thus effectively improved the photocatalytic activity of the composite.

The improvement in charge carrier separation was evaluated using the photoluminescence (PL) spectra (Fig. 5(d)). Pure $\mathrm{TiO}_{2}$ clearly exhibited stronger emission intensity than pristine $\mathrm{SnS}_{2}$, suggesting that the photo-generated charge carrier separation was poorer in $\mathrm{TiO}_{2}$. Interestingly, formation of the binary $\mathrm{SnS}_{2} / \mathrm{TiO}_{2}$ composite led to slightly decreased emission intensity compared with those of the single components. Upon the introduction of the rGO interlayer, the TGS- 4 composite exhibited obviously reduced signal intensity, which suggested significantly accelerated dissociation of the photo-induced charge carriers at the interfaces between the rGO interlayer and the $\mathrm{SnS}_{2} / \mathrm{TiO}_{2}$ composite [42]. Additionally, the periodic on/off photocurrent response is a main indicator used to evaluate the recombination rate of photo-generated electron-hole pairs. As shown in Fig. 5(e), the transient photocurrent of the pristine $\mathrm{TiO}_{2}$ was negligible. After loading an appropriate amount of $\mathrm{SnS}_{2}$, the photocurrent density value of the TS-2 composite reached $5.91 \mu \mathrm{A} \mathrm{cm}-2$. The introduction of an rGO interlayer between $\mathrm{TiO}_{2}$ and $\mathrm{SnS}_{2}$ significantly improved the transient photocurrent. The optimized TGS-4 composite displayed the highest photocurrent density value of $28.25 \mu \mathrm{A} \mathrm{cm}{ }^{-2}$, indicating that the $\mathrm{rGO}$ interlayer could effectively promote interfacial charge separation and transfer. Moreover, the excellent charge mobility in the TGS-4 composite was also verified from the electrochemical impedance spectra (EIS). As shown in Fig. 5(f), the TGS-4 composite displayed a smaller semicircle diameter than the pristine $\mathrm{TiO}_{2}$ and $\mathrm{SnS}_{2}$ or the TS- 2 composite, implying that the presence of the rGO interlayer remarkably improved the interfacial charge-separation efficiency of the hierarchical porous $\mathrm{SnS}_{2} / \mathrm{rGO} / \mathrm{TiO}_{2}$ hollow sphere heterojunctions.

Furthermore, the energy level structure, work functions $\left(W_{\mathrm{s}}\right)$, and corresponding Fermi levels $\left(E_{\mathrm{f}}\right)$ of the hybrid heterojunction were thoroughly investigated using ultraviolet photoelectron spectroscopy (UPS) and Mott-Schottky plots. As demonstrated in Figs. 6(a)-(d) and Fig. S8, all the ionization potentials [equivalent to the valence band energy $\left(E_{\mathrm{VB}}\right)$ ] of the samples were evaluated by subtracting the width of the He I UPS spectra from the excitation energy (21.22 eV) [43-45]. Based on the second electron cutoff edge ( $\left.E_{\text {cutoff }}\right)$ positions and the valence-band onset $\left(E_{\mathrm{F}}\right)$ relative to the $E_{\mathrm{f}}$, the $W \mathrm{~s}$ of $\mathrm{TiO}_{2}$ and $\mathrm{SnS}_{2}$ were calculated to be 4.01 and $4.65 \mathrm{eV}$ vs. vacuum level (Vac), respectively; these values were smaller than that of the rGO interlayer ( $5.56 \mathrm{eV} v s$. Vac). In addition, the $E_{\mathrm{VB}}$ values of $\mathrm{TiO}_{2}$ and $\mathrm{SnS}_{2}$ were calculated to be -7.12 and $-6.53 \mathrm{eV}$ vs. Vac, respectively. By combining these results with the band gaps determined from the UV-vis DRS spectra, the conduction band (CB) positions $\left(E_{\mathrm{CB}}\right)$ of $\mathrm{TiO}_{2}$ and $\mathrm{SnS}_{2}$ were estimated to be -3.92 and $-4.46 \mathrm{eV}$ vs. Vac, respectively. From the 

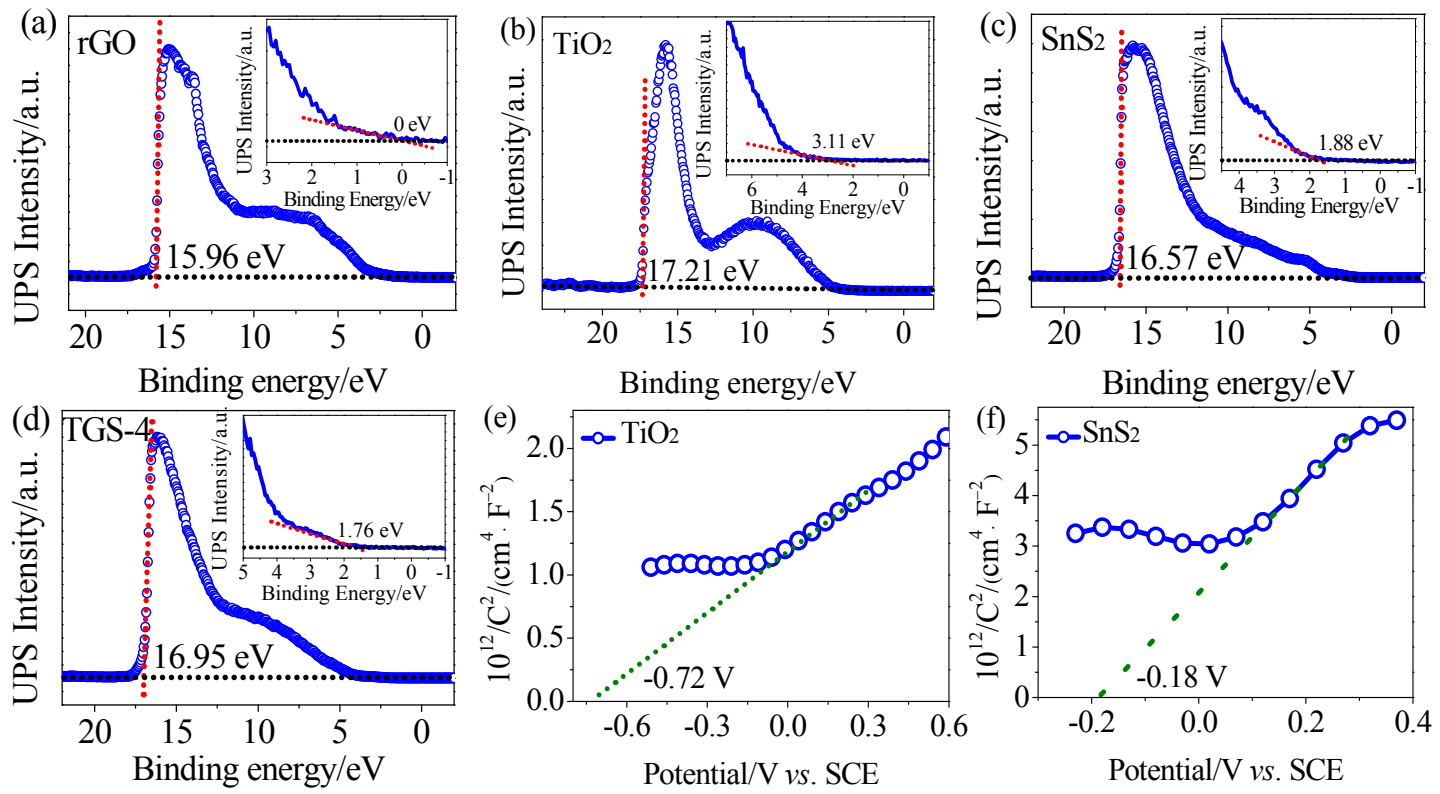

Fig. 6. (a-d) UPS spectra of the different samples; Mott-Schottky plots of $\mathrm{TiO}_{2}$ (e) and $\mathrm{SnS}_{2}$ (f) in $2 \mathrm{moL} \mathrm{L}^{-1} \mathrm{Na}_{2} \mathrm{SO}_{4}$ electrolytes.

Mott-Schottky plots, which exhibited positive slopes (Figs. 6(e) and (f)), the flat-band potentials $\left(E_{\mathrm{fb}}\right)$ of $\mathrm{TiO}_{2}$ and $\mathrm{SnS}_{2}$ were measured to be -0.72 and $-0.18 \mathrm{~V}$ vs. the saturated calomel electrode (SCE), respectively [46,47]. As for n-type semiconductor, the bottom position of the $\mathrm{CB}$ is consistent with the $E_{\mathrm{fb}}$ [48-50]. Using the standard conversion factors that $0 \mathrm{~V} v$ s. SCE equals $0.241 \mathrm{~V} v s$. the reversible hydrogen electrode (NHE) and $0 \mathrm{~V}$ vs. NHE equals $-4.44 \mathrm{eV} v s$. Vac, the $E_{\mathrm{CB}}$ values of $\mathrm{TiO}_{2}$ and $\mathrm{SnS}_{2}$ were estimated to be -0.479 and $+0.061 \mathrm{~V} v$ s. NHE using Mott-Schottky curves; these values correspond to -3.961 and $-4.501 \mathrm{eV} v s$. Vac, respectively. The results of the Mott-Schottky curve analysis further confirmed the accuracy of the above UPS analysis.

\subsection{Photocatalytic mechanism}

Based on the calculated parameters of the energy-level structure (Table S1), the energy level alignments of the TS-2 and TGS-4 composites and the corresponding photo-induced charge carrier transmission route were proposed. Normally, when $\mathrm{SnS}_{2}$ is directly anchored on the surface of $\mathrm{TiO}_{2}$, electrons should flow across the interface from $\mathrm{TiO}_{2}$ to $\mathrm{SnS}_{2}$ until their $E_{\mathrm{f}}$ reach the same level due to the higher $W_{\mathrm{S}}$ of $\mathrm{SnS}_{2}$. As shown in Fig. 7(a), after achieving Fermi equilibrium, a space charge region is formed close to the $\mathrm{SnS}_{2} / \mathrm{TiO}_{2}$ interface, which leads to a built-in interfacial electric field directed from $\mathrm{TiO}_{2}$ towards $\mathrm{SnS}_{2}$. The induced built-in electric field would generate a different potential distribution at each point in the space charge region. The additional surface potential would cause upward band bending in $\mathrm{TiO}_{2}$ and have the opposite effect in $\mathrm{SnS}_{2}$. Under visible light irradiation, only $\mathrm{SnS}_{2}$ would be photo-excited to produce photo-generated electrons and holes. The interfacial potential barrier induced by the band bending, as well as the smaller $\mathrm{CB}$ and VB potentials of $\mathrm{SnS}_{2}$, would simultaneously impede the injection of the photo-excited electrons and holes from the $\mathrm{CB}$ and $\mathrm{VB}$ of $\mathrm{SnS}_{2}$ into those of $\mathrm{TiO}_{2}$, respectively. Thus, this strategy is not effective for decreasing the high efficiency recombination of photo-generated charge carriers on $\mathrm{SnS}_{2}$. As a result, the binary $\mathrm{SnS}_{2} / \mathrm{TiO}_{2}$ composite displayed unsatisfactory photocatalytic activity compared to that of pure
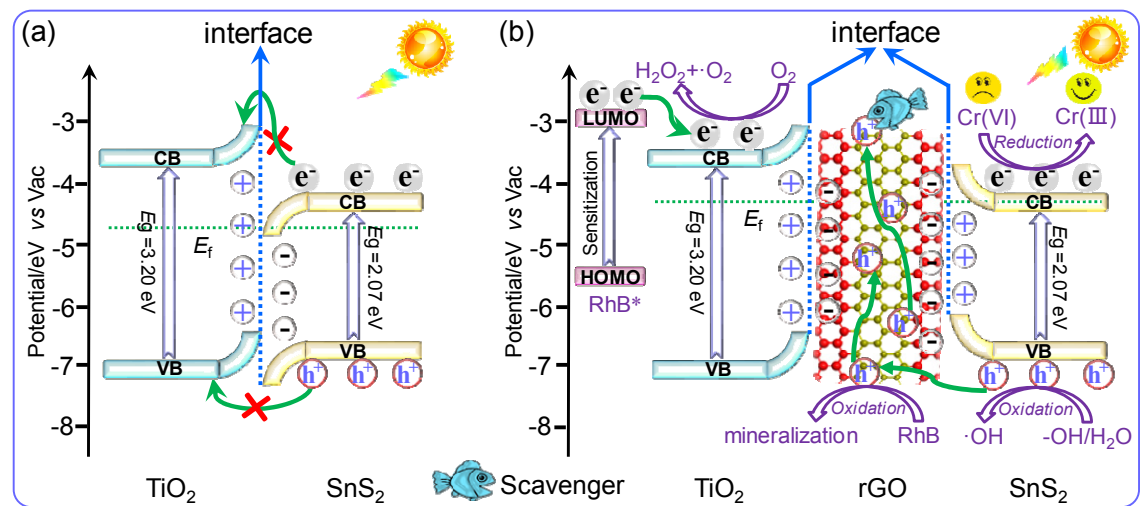

Fig. 7. Schematic of the energy level alignment and corresponding charge transfer process in the TS-2 (a) and TGS-4 (b) composites during the photoredox reactions. 
$\mathrm{SnS}_{2}$. Encouragingly, this was not the case when an rGO interlayer was inserted between the $\mathrm{TiO}_{2}$ shell and the outermost $\mathrm{SnS}_{2}$ layer. As shown in Fig. 7(b), in the ternary composite, the electrons would flow from $\mathrm{TiO}_{2}$ and $\mathrm{SnS}_{2}$ across the respective interfaces to the rGO interlayer until their $E_{\mathrm{f}}$ reached equilibrium due to the higher $W_{\mathrm{s}}$ of rGO. This behavior would favor the formation of dual built-in electric fields at the space charge regions close to the $\mathrm{TiO}_{2} / \mathrm{rGO}$ and $\mathrm{SnS}_{2} / \mathrm{rGO}$ interfaces; the direction of these fields would be from $\mathrm{TiO}_{2}$ and $\mathrm{SnS}_{2}$ towards rGO. Under the influence of the built-in electric fields, the different potential distribution at each point in the space charge region would increase the surface potential, resulting in upward band bending in both $\mathrm{TiO}_{2}$ and $\mathrm{SnS}_{2}$. Under visible light illumination, the interfacial potential barrier induced by the band bending and built-in electric fields would have a negative influence on photo-induced electron transfer, causing the photo-induced electrons to remain in the $\mathrm{CB}$ of the $\mathrm{SnS}_{2}$. In contrast, the built-in electric field would facilitate photo-induced hole injection from the $\mathrm{VB}$ of $\mathrm{SnS}_{2}$ into the rGO interlayer. Therefore, the $\mathrm{rGO}$ interlayer acted as a classic hole injection layer rather than an electron transfer mediator, which significantly facilitated the spatial separation and rapid migration of photo-induced charge carriers in the $\mathrm{SnS}_{2}$.

During the $\mathrm{RhB}$ photodegradation process, the photosensitive $\mathrm{RhB}$ can easily be excited to $\mathrm{RhB}^{*}[51,52]$. The photo-excited electrons in the lowest unoccupied molecular orbital (LUMO) of RhB could spontaneously transfer to the CBs of both $\mathrm{TiO}_{2}$ and $\mathrm{SnS}_{2}$ due to the more positive LUMO potential of $\mathrm{RhB}$ $(-3.08 \mathrm{eV} v$ s. Vac). Notably, the dissolved oxygen could only be directly reduced to form $\cdot \mathrm{O}^{2-}$ by the electrons accumulated on the $\mathrm{CB}$ of $\mathrm{TiO}_{2}$, and not by those of $\mathrm{SnS}_{2}$, because the CB potential of $\mathrm{SnS}_{2}$ is more negative than that of $\mathrm{TiO}_{2}(-3.92 \mathrm{eV} v s$. Vac $)$ and the reduction potential of $\mathrm{O}_{2} / \cdot \mathrm{O}^{2-}(-4.45 \mathrm{eV} v \mathrm{~s}$. Vac $)$. The generated $\cdot \mathrm{O}^{2-}$ would mineralize the $\mathrm{RhB}^{*}$ to form intermediate products or the ultimate products $\mathrm{CO}_{2}$ and $\mathrm{H}_{2} \mathrm{O}$ [53]. However, the results of the trapping experiments indicated that $\bullet \mathrm{O}^{2-}$ was not the dominant active species. Meanwhile, the photo-induced holes accumulated on the rGO interlayer could be rapidly captured by $\mathrm{H}_{2} \mathrm{O}$ to yield $\bullet \mathrm{OH}$ radicals due to the more positive oxidation potential of $-\mathrm{OH} / \bullet \mathrm{OH}(-6.49 \mathrm{eV} v \mathrm{vs}$. Vac) compared to the VB potential of $\mathrm{SnS}_{2}$. Undoubtedly, both the photo-induced holes and $\cdot \mathrm{OH}$ have strong oxidation ability and can directly decompose the RhB molecules.

Similarly, the spatial separation and directional migration of the photo-induced electron-hole pairs between $\mathrm{TiO}_{2} / \mathrm{SnS}_{2}$ and the $\mathrm{rGO}$ interlayer are favorable for the photoreduction of $\mathrm{Cr}(\mathrm{VI})$ in the TGS-4 composites. Since the calculated CB potential of $\mathrm{SnS}_{2}$ is more positive than that of $\mathrm{Cr}(\mathrm{VI}) / \mathrm{Cr}(\mathrm{III})(-5.01 \mathrm{eV}$ vs. Vac) [54], photoreduction of $\mathrm{Cr}(\mathrm{VI})$ by the photo-generated electrons would be the dominant pathway. The photo-generated holes accumulated on the rGO interlayer could be quenched directly by the hole scavenger. In short, the inserted rGO interlayer can serve as an efficient hole-transport layer. The synergistic effects of the hierarchical hollow structure, matched band alignment, and built-in interfacial electric field resulted in beneficial effects on the light-harvesting efficiency, spatial charge separation, and directional charge transfer in the ternary $\mathrm{SnS}_{2} / \mathrm{rGO} / \mathrm{TiO}_{2}$ hollow sphere heterojunction, which were responsible for its high photocatalytic activity.

\section{Conclusions}

In summary, a novel modified "silica-protected calcination" method was adopted to prepare a hierarchical porous $\mathrm{SnS}_{2} / \mathrm{rGO} / \mathrm{TiO}_{2}$ hollow sphere heterojunction. The optimized hybrid system with a 2 wt\% rGO loading exhibited superior visible-light-driven photocatalytic performance and durability for $\mathrm{RhB}$ decomposition and $\mathrm{Cr}(\mathrm{VI})$ reduction compared to pure $\mathrm{TiO}_{2}$, pure $\mathrm{SnS}_{2}$, or a binary $\mathrm{SnS}_{2} / \mathrm{TiO}_{2}$ composite. The advantageous hierarchical porous hollow structure not only improved the light absorption capability, but also exposed more active sites. Most importantly, the rGO interlayer inserted between $\mathrm{TiO}_{2}$ and $\mathrm{SnS}_{2}$ was an efficient hole-transporting layer, which was beneficial to the spatial charge separation and directional transfer at the interface of the tandem heterojunction. This novel design strategy prolonged the lifetime of the photo-induced charge carriers, and should provide new pathways to enhance photocatalytic activity in wastewater treatment.

\section{Conflict of interest}

The authors declare no conflict of interest.

\section{Appendix A. Supplementary data}

Supplementary data associated with this article can be found in the online version.

\section{References}

[1] L. Yang, J. Huang, L. Shi, L. Cao, H. Liu, Y. Liu, Y. Li, H. Song, Y. Jie, J. Ye, Appl. Catal. B, 2018, 221, 670-680.

[2] L. Han, Y.-L. Zhong, K. Lei, D. Mao, Y.-Z. Dong, G. Hong, Y.-T. Zhou, D. Fang, J. Phys. Chem. C, 2019, 123, 2398-2409.

[3] M.-H. Wu, L. Li, Y.-C. Xue, G. Xu, L. Tang, N. Liu, W.-Y. Huang, Appl. Catal. B, 2018, 228, 103-112.

[4] D. Cao, H. An, X. Yan, Y. Zhao, G. Yang, H. Mei, Acta Phys.-Chim. Sin., 2020, 36, 1901051.

[5] X. Shi, Z. Lou, P. Zhang, M. Fujitsuka, T. Majima, ACS Appl. Mater. Interfaces, 2016, 8, 31738-31745.

[6] B. Sun, W. Zhou, H. Li, L. Ren, P. Qiao, W. Li, H. Fu, Adv. Mater., 2018, 30, e1804282.

[7] P. Zhang, X. W. D. Lou, Adv. Mater., 2019, 31, e1900281.

[8] M. Xiao, Z. Wang, M. Lyu, B. Luo, S. Wang, G. Liu, H. M. Cheng, L. Wang, Adv. Mater., 2018, e1801369.

[9] Q. Sun, N. Wang, J. Yu, J. C. Yu, Adv. Mater., 2018, 30, e1804368.

[10] S. Wang, B. Y. Guan, X. Wang, X. W. D. Lou, J. Am. Chem. Soc., 2018, 140, 15145-15148.

[11] M. Xing, B. Qiu, M. Du, Q. Zhu, L. Wang, J. Zhang, Adv. Funct. Mater., 2017, 27, 1702624.

[12] L. Ling, L. Liu, Y. Feng, J. Zhu, Z. Bian, Chin. J. Catal., 2018, 39, 639-645.

[13] X. Chen, R. Shi, Q. Chen, Z. Zhang, W. Jiang, Y. Zhu, T. Zhang, Nano Energy, 2019, 59, 644-650.

[14] Y. Al Salka, L. I. Granone, W. Ramadan, A. Hakki, R. Dillert, D. W. Bahnemann, Appl. Catal. B, 2019, 244, 1065-1095. 


\section{Graphical Abstract}

Chin. J. Catal., 2021, 42: 583-594 doi: 10.1016/S1872-2067(20)63649-X

Accelerating directional charge separation via built-in interfacial electric fields originating from work-function differences

Chao Xue, Hua An, Guosheng Shao, Guidong Yang*

Zhengzhou University; Xi'an Jiaotong University

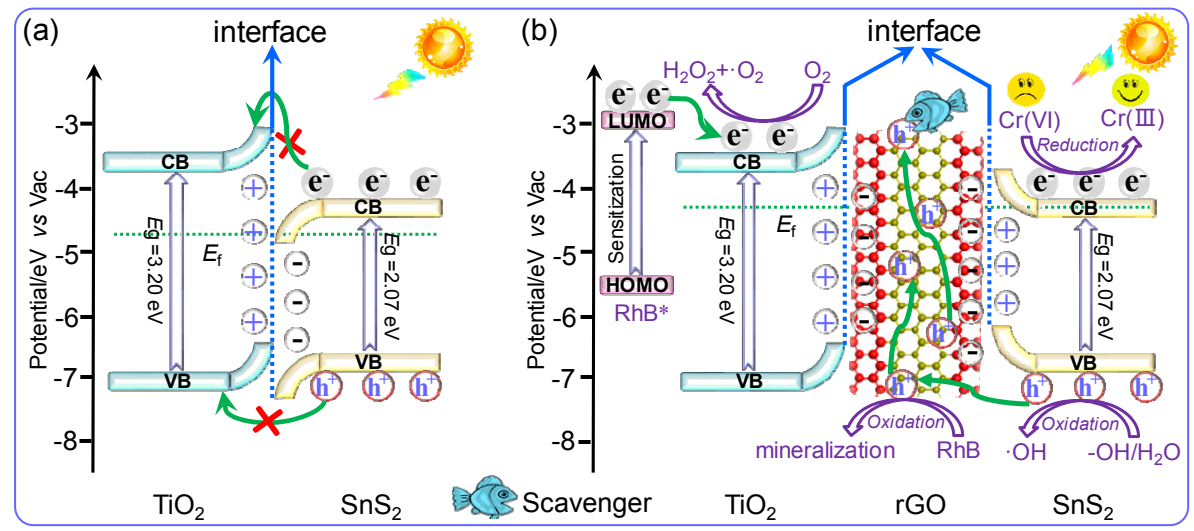

The built-in interfacial electric fields originating from differences in the work-functions facilitate the directional migration of photo-induced holes from the VB of $\mathrm{SnS}_{2}$ to the rGO hole injection interlayer, leading to efficient charge separation and high photocatalytic activity.

[15] G. D. Gesesse, C. Li, E. Paineau, Y. Habibi, H. Remita, C. Colbeau-Justin, M. N. Ghazzal, Chem. Mater., 2019, 31, 4851-4863.

[16] J. Pan, Z. Guan, J. Yang, Q. Li, Chin. J. Catal., 2020, 41, 200-208.

[17] B. Srinivas, M. A. Pandit, K. Muralidharan, ACS Omega, 2019, 4, 14970-14980.

[18] X. Jiao, X. Li, X. Jin, Y. Sun, J. Xu, L. Liang, H. Ju, J. Zhu, Y. Pan, W. Yan, Y. Lin, Y. Xie, J. Am. Chem. Soc., 2017, 139, 18044-18051.

[19] G. Li, R. Su, J. Rao, J. Wu, P. Rudolf, G. R. Blake, R. A. Groot, F. Besenbacher, T. T. M. Palstra, J. Mater. Chem. A, 2016, 4, 209-216.

[20] Z. Xie, H. L. Tan, X. Wen, Y. Suzuki, A. Iwase, A. Kudo, R. Amal, J. Scott, Y. H. Ng, ACS Appl. Mater. Interfaces, 2019, 11, 23125-23134.

[21] E. Jokar, Z. Y. Huang, S. Narra, C.-Y. Wang, V. Kattoor, C.-C. Chung, E. W.-G. Diau, Adv. Energy Mater., 2018, 8, 1701640.

[22] J. Liu, Y. Xue, Y. Gao, D. Yu, M. Durstock, L. Dai, Adv. Mater., 2012, $24,2228-33$.

[23] S. Ye, C. Ding, R. Chen, F. Fan, P. Fu, H. Yin, X. Wang, Z. Wang, P. Du, C. Li, J. Am. Chem. Soc., 2018, 140, 3250-3256.

[24] L. Xu, W.-Q. Huang, L.-L. Wang, Z.-A. Tian, W. Hu, Y. Ma, X. Wang, A. Pan, G.-F. Huang, Chem. Mater., 2015, 27, 1612-1621.

[25] D. Yang, L. Zhou, W. Yu, J. Zhang, C. Li, Adv. Energy Mater., 2014, 4, 1400591.

[26] J. B. Joo, Q. Zhang, I. Lee, M. Dahl, F. Zaera, Y. Yin, Adv. Funct. Mater., 2012, 22, 166-174.

[27] D. Zhou, Z. Cai, X. Lei, W. Tian, Y. Bi, Y. Jia, N. Han, T. Gao, Q. Zhang, Y. Kuang, J. Pan, X. Sun, X. Duan, Adv. Energy Mater., 2018, 8, 1701905.

[28] C. Xue, H. Li, H. An, B. Yang, J. Wei, G. Yang, ACS Catal, 2018, 8, $1532-1545$.

[29] C. Xue, X. Yan, H. An, H. Li, J. Wei, G. Yang, Appl. Catal. B, 2018, 222, 157-166.

[30] W. Lu, D. Wang, L. Guo, Y. Jia, M. Ye, J. Huang, Z. Li, Y. Peng, W. Yuan, X. Chen, Adv. Mater, 2015, 27, 7986-7991.
[31] M. Wang, L. Cai, Y. Wang, F. Zhou, K. Xu, X. Tao, Y. Chai, J. Am. Chem. Soc., 2017, 139, 4144-4151.

[32] X. Liu, D. Chao, D. Su, S. Liu, L. Chen, C. Chi, J. Lin, Z. X. Shen, J. Zhao, L. Mai, Y. Li, Nano Energy, 2017, 37, 108-117.

[33] Y. Lei, C. Yang, J. Hou, F. Wang, S. Min, X. Ma, Z. Jin, J. Xu, G. Lu, K.-W. Huang, Appl. Catal. B, 2017, 216, 59-69.

[34] T. Wu, L. Zou, D. Han, F. Li, Q. Zhang, L. Niu, Green Chem., 2014, 16, 2142-2146.

[35] Z. Xiong, Y. Luo, Y. Zhao, J. Zhang, C. Zheng, J. C. Wu, Phys. Chem. Chem. Phys., 2016, 18, 13186-95.

[36] Q. Lang, Y. Chen, T. Huang, L. Yang, S. Zhong, L. Wu, J. Chen, S. Bai, Appl. Catal. B, 2018, 220, 182-190.

[37] Z. Yue, A. Liu, C. Zhang, J. Huang, M. Zhu, Y. Du, P. Yang, Appl. Catal. $B, 2017,201,202-210$.

[38] C. Liu, Y. Fu, J. Zhao, H. Wang, H. Huang, Y. Liu, Y. Dou, M. Shao, Z. Kang, Chem. Eng. J., 2019, 358, 134-142.

[39] I. Shown, S. Samireddi, Y. C. Chang, R. Putikam, P. H. Chang, A. Sabbah, F. Y. Fu, W. F. Chen, C. I. Wu, T. Y. Yu, P. W. Chung, M. C. Lin, L. C. Chen, K. H. Chen, Nat. Commun., 2018, 9, 169.

[40] C. Xue, T. Zhang, S. Ding, J. Wei, G. Yang, ACS Appl. Mater. Interfaces, 2017, 9, 16091-16102.

[41] Y. Chao, P. Zhou, N. Li, J. Lai, Y. Yang, Y. Zhang, Y. Tang, W. Yang, Y. Du, D. Su, Y. Tan, S. Guo, Adv. Mater., 2019, 31, e1807226.

[42] W. Liu, L. Cao, W. Cheng, Y. Cao, X. Liu, W. Zhang, X. Mou, L. Jin, X. Zheng, W. Che, Q. Liu, T. Yao, S. Wei, Angew. Chem. Int. Ed., 2017, 56, 9312-9317.

[43] C. Zhu, C. Liu, Y. Zhou, Y. Fu, S. Guo, H. Li, S. Zhao, H. Huang, Y. Liu, Z. Kang, Appl. Catal. B, 2017, 216, 114-121.

[44] J. Liu, Y. Liu, N. Liu, Y. Han, X. Zhang, H. Huang, Y. Lifshitz, S.-T. Lee, J. Zhong, Z. Kang, Science, 2015, 347, 970-974.

[45] J. Barbe, M. L. Tietze, M. Neophytou, B. Murali, E. Alarousu, A. E. Labban, M. Abulikemu, W. Yue, O. F. Mohammed, I. McCulloch, A. Amassian, S. Del Gobbo, ACS Appl. Mater. Interfaces, 2017, 9, 
11828-11836.

[46] Z. Jiang, W. Wan, H. Li, S. Yuan, H. Zhao, P. K. Wong, Adv. Mater., 2018, 30, 1706108

[47] T. F. Yeh, C. Y. Teng, S. J. Chen, H. Teng, Adv. Mater., 2014, 26, 3297-303.

[48] L. Pan, S. Wang, J. Xie, L. Wang, X. Zhang, J.-J. Zou, Nano Energy, 2016, 28, 296-303.

[49] W. Zhen, X. Ning, B. Yang, Y. Wu, Z. Li, G. Lu, Appl. Catal. B, 2018,
221, 243-257.

[50] K. Chang, X. Hai, H. Pang, H. Zhang, L. Shi, G. Liu, H. Liu, G. Zhao, M. Li, J. Ye, Adv. Mater., 2016, 28, 10033-10041.

[51] C. Xue, X. Xu, G. Yang, S. Ding, RSC Adv., 2015, 5, $102228-102237$.

[52] C. Xue, X. Yan, S. Ding, G. Yang, RSC Adv., 2016, 6, 68653-68662.

[53] J. Li, Y. Xie, Y. Zhong, Y. Hu, J. Mater. Chem. A, 2015, 3, 5474-5481.

[54] R. Liang, L. Shen, F. Jing, W. Wu, N. Qin, R. Lin, L. Wu, Appl. Catal. B, 2015, 162, 245-251.

\title{
源于功函数差异的界面内建电场调控载流子定向分离的作用机制研究
}

\author{
薛 超 ${ }^{\mathrm{a}}$, 安 华 ${ }^{\mathrm{b}}$, 郡国胜 ${ }^{\mathrm{a}}$, 杨贵东 $\mathrm{b}^{*}$ \\ a 郑州大学材料科学与工程学院, 国家低碳环保材料智能设计国际联合研究中心, 河南郑州450001 \\ b西安交通大学化学工程与技术学院, 西安交通大学-牛津大学催化国际联合实验室, 陕西西安710049
}

\begin{abstract}
摘要: 近年来, 由有机污染物和重金属引起的水污染对人类健康、生态系统和社会可持续发展构成了严重威胁. 而光催化 技术以其高效、低成本、节能、无二次污染等优点成为解决日益严重的环境污染问题的一个极具吸引力的策略. 众所周 知, 宽光谱吸收、高效载流子分离和快速的表面反应动力学是高性能光催化剂所必备的基本条件. 而多孔 $\mathrm{TiO}_{2}$ 空心球具有 以下结构优势: (1)成本低、无毒、氧化还原电位适中、物理化学性质稳定; (2)中空结构有利于入射光多重散射, 而且大表 面积可以暴露更多的活性位点; (3)多孔结构有利于传质过程. 但是, 窄光谱吸收和低的光生载流子分离效率严重阻碍了空 心结构 $\mathrm{TiO}_{2}$ 的实际应用. 因此, 通过耦合窄带隙半导体构建异质结光催化剂可以有效提高光吸收和促进光生电荷的分离. 窄带隙 $\left(E_{\mathrm{g}}=2.18-2.44 \mathrm{eV}\right)$ 半导体材料 $\mathrm{SnS}_{2}$ 具有无毒、化学性质稳定、低成本和宽谱响应等诸多优点. 若将超薄 $\mathrm{SnS}_{2}$ 纳米片 锚定生长在多孔 $\mathrm{TiO}_{2}$ 空心球表面, 将对异质结的光催化性能产生显著的影响. 一方面, 分级结构的空心球具有高可见光捕 获率; 另一方面, 超薄 $\mathrm{SnS}_{2}$ 纳米片具有更短的载流子扩散距离, 从而有效地抑制光生载流子在催化剂体相内部复合. 然而, 由于其能带结构的限制, 二元 $\mathrm{TiO}_{2} / \mathrm{SnS}_{2}$ 复合材料很容易形成嵌入式I型异质结, 在很大程度上降低了光催化氧化还原能力. 此外, 在光催化剂表面聚集的光生电子和空穴容易发生随机性复合. 因此, 迫切需要通过引入界面驱动力来调节表面载流 子的分离和转移. 众多研究表明, 通过化学功能化可以实现对还原氧化石墨烯( $\mathrm{rGO}$ )的能带结构、功函数、电导率、亲水性 和光学性质的调控. 功能化的 $\mathrm{rGO}$ 可以作为优良的空穴提取材料, 在 $\mathrm{rGO}$ 两侧分别耦合不同能级结构的半导体光催化材料, 通过异质界面能级和功函数差异带来的界面内建电场, 精确调控光生载流子在界面间的空间分离和定向迁移.

基于上述分析, 本文通过改进的“硅保护煅烧”方法合成了分级多孔 $\mathrm{SnS}_{2} / \mathrm{rGO} / \mathrm{TiO}_{2}$ 空心球异质结光催化剂. 分级多孔 空心球的结构优势不仅增强其光捕获能力, 而且为光氧化还原反应提供了丰富的活性位点. 特别是, 在 $\mathrm{TiO}_{2}$ 和 $\mathrm{SnS}_{2}$ 纳米薄 片之间嵌入的 $\mathrm{rGO}$ 中间层可以作为空穴注入层. 由不同功函数导致的界面内建电场可以精确地调控光生空穴从 $\mathrm{SnS}_{2}$ 纳米 薄片的价带向 $\mathrm{rGO}$ 空穴注入层定向迁移, 显著延长了光生载流子的寿命. 在可见光照射下, 负载 $2 \mathrm{wt} \% \mathrm{rGO}$ 的分级多孔 $\mathrm{SnS}_{2} / \mathrm{rGO} / \mathrm{TiO}_{2}$ 空心球异质结光催化剂对罗丹明B染料的降解率可达 $97.3 \%$, 对 $\mathrm{Cr}(\mathrm{VI})$ 的还原效率可达 $97.09 \%$. 此外, 经过六 个周期的循环实验, 该异质结催化降解罗丹明 $\mathrm{B}$ 和还原 $\mathrm{Cr}(\mathrm{VI})$ 的效率没有明显降低, 表现出较好的光催化稳定性.
\end{abstract}

关键词: $\mathrm{SnS}_{2} / \mathrm{rGO} / \mathrm{TiO}_{2}$; 空心球; 光催化剂; 空穴注入层; $\mathrm{Cr}(\mathrm{VI})$ 还原

收稿日期: 2020-04-29. 接受日期: 2020-05-26. 上网时间: 2020-09-05.

*通讯联系人. 电话/传真: (029)82668658; 电子信箱: guidongyang@xjtu.edu.cn

基金来源：国家自然科学基金(U1862105); 河南省重点研发与推广专项(科技攻关)(202102210053); 中国博士后科学基金 (2019M662515); 王宽诚教育基金.

本文的电子版全文由Elsevier出版社在ScienceDirect上出版(http://www.sciencedirect.com/science/journal/18722067). 